Document downloaded from:

http://hdl.handle.net/10251/157306

This paper must be cited as:

Gonzalez-Camejo, J.; Paches Giner, MAV.; Marín, A.; Jiménez Benítez, AL.; Seco, A.; Barat, R. (2020). Production of microalgal external organic matter in a Chlorella-dominated culture: influence of

temperature and stress factors. Environmental Science: Water Research \& Technology. (7):1-14. https://doi.org/10.1039/d0ew00176g

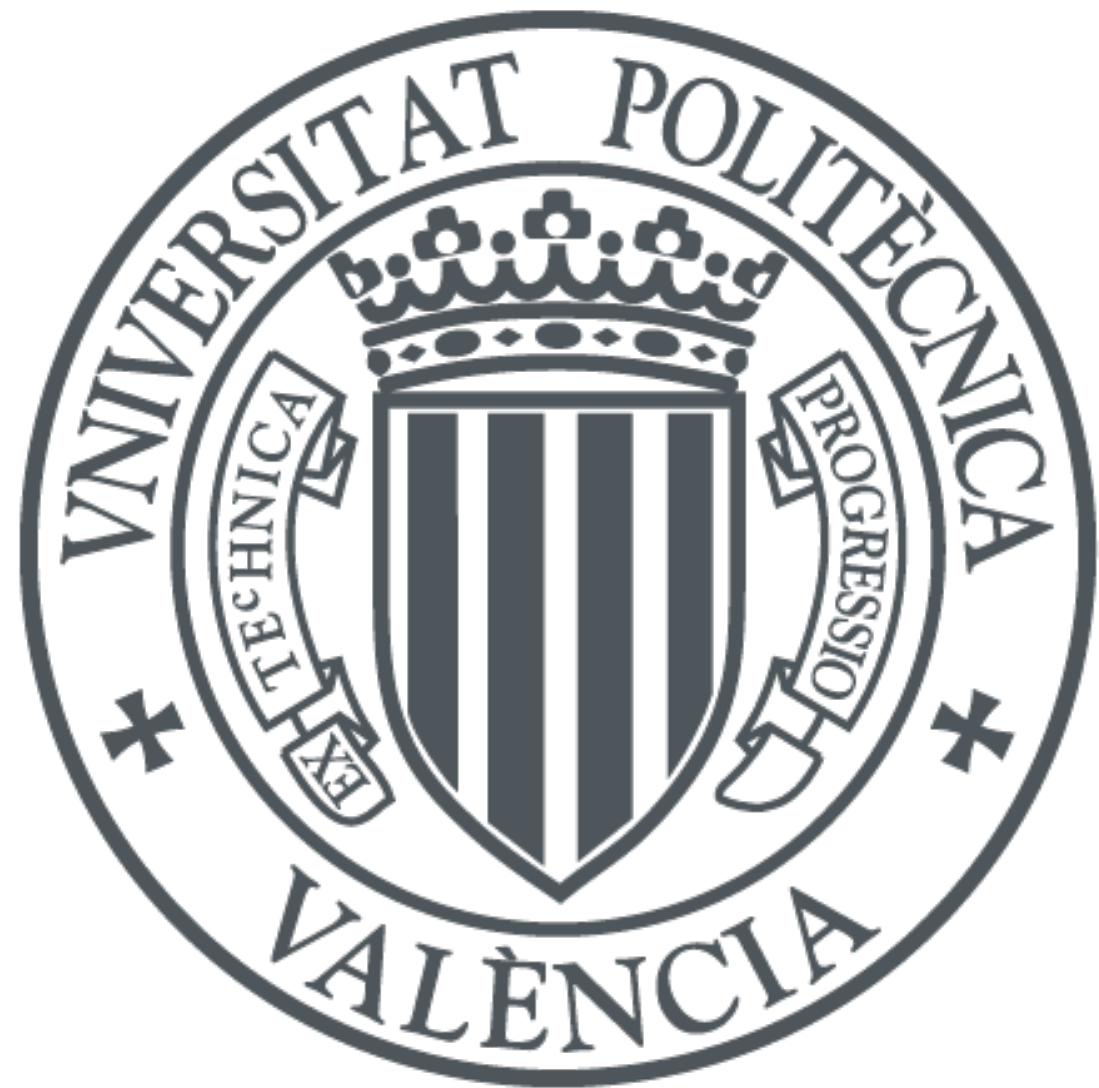

The final publication is available at

https://doi.org/10.1039/d0ew00176g

Copyright The Royal Society of Chemistry

Additional Information 


\title{
Production of microalgal external organic matter in a Chlorella-dominated culture: influence of temperature and stress factors
}

\author{
J. González-Camejo a , M. Pachés ${ }^{a^{*}}$, A. Marína ${ }^{a}$ A. Jiménez-Benítez ${ }^{a}, A$. Seco $^{b}$ and R. Barat ${ }^{a}$.
}

\author{
Affiliations \\ ${ }^{a}$ CALAGUA - Unidad Mixta UV-UPV, Institut Universitari d'Investigació d'Enginyeria de l'Aigua $i$ \\ Medi Ambient - IIAMA, Universitat Politècnica de València, Camí de Vera s/n, 46022 Valencia, \\ Spain. \\ ${ }^{b}$ CALAGUA - Unidad Mixta UV-UPV, Departament d'Enginyeria Química, Universitat de \\ València, Avinguda de la Universitat s/n, 46100 Burjassot, Valencia, Spain. \\ ${ }^{*}$ Corresponding author Email address: mapacgi@upvnet.upv.es (M. Pachés)
}

\begin{abstract}
Although microalgae are recognised to release external organic matter (EOM), little is known about this phenomenon in microalgae cultivation systems, especially at large scale.A study was carried out on the effect of microalgae-stressing factors such as temperature, nutrient limitation and ammonium oxidising bacteria (AOB) competition in EOM production by microalgae. The results showe non-statistically significant differences in EOM production at constant temperatures of 25 , 30 and $35^{\circ} \mathrm{C}$. However, when the temperature was raise fro 25 to $35^{\circ} \mathrm{C}$ for $4 \mathrm{~h}$ a day polysaccharide production increased significantly, indicating microalgae stress. Nutrient limitation also seemed to increased EOM production. No significant differences were found in EOM production under lab conditions when the

microalgae competed with $A O B$ for ammonium uptake. However, when EOM concentration was monitored during continuous outdoor operation of a membrane photobioreactor (MPBR) plant, nitrifying bacteria activity was likely to be responsible for the increase in EOM concentration in the culture. Other factors such as high temperatures, ammonium-depletion and low light intensities could also have induced cell deterioration and thus have influenced EOM production in the outdoor MPBR plant. Membrane fouling seemed to depend on the biomass concentration of the culture. However, under the operating conditions tested, the behaviour of fouling rate with respect to EOM concentration was different depending on the initial membrane state.
\end{abstract}

\section{Water impact}

Microalgae bioremediation is attracting increased attention due to their ability of recovering nutrients from wastewater while producing valuable biomass. However, microalgae cultivation has to deal with the production of external organic matter (EOM), which is ofte not considered. The aim of this study is to assess the conditions that increase the production of EOM by microalgae, which still remains unclear.

\section{Introduction}

The recent interest in developing new sustainable technologies within the circular economy concept has boosted research on novel water resource recovery facilities (WRRF), where sewage is not considered as a waste that has to be treated but as a source of energy, nutrients and reclaimed water, resulting in environmental and economic benefits.1,2 One possible solution to make this transition to WRRFs is the combination between anaerobic membrane bioreactor (AnMBR) systems with microalgae cultivation technology.3 AnMBRs have been

tested as a promising energy-effective technology to treat sewage since they can obtain biogas from the anaerobic digestion of the organic matter.4,2 However, AnMBR effluents usually present large nutrient contents5 that can lead to eutrophication.6 A post-treatment step is therefore needed when emitting to sensitive areas. In this respect, microalgae have appeared as a suitable option for wastewater remediation7-9 as they are able to reduce the nutrient content of these AnMBR effluents.10,11 In addition, microalgae biomass can serve as a renewable source of biofuels, biofertilisers and other valuable products.12-15 From all the microalgae reported in the literature, the green microalgae Chlorella is one of the genus that have shown higher adaptability to wastewater. 16,17,7 To cultivate microalgae under outdoor conditions, membrane photobioreactors (MPBRs), which consists of the combination of closed PBRs and membrane filtration,18 have 
appeared as promising technology.10 PBRs are designed to attain high photosynthetic efficiencies, biomass productivities and nutrient removal rates, 19 while membrane filtration enables to operate the system at lower hydraulic retention time (HRT), hence reducing the surface area needed to cultivate microalgae.20,11 Filtration entails membrane fouling due to the accumulation of microalgae biomass on the membrane (cake-layer) and the partial block of the internal pores, 2123 which reduces the filtration efficiency and increases the energy consumption of the process.24,25 It must be noted that membrane fouling can be more severe due to the release of microalgal external organic matter (EOM) into the medium since it can intensify the cake layer formation or the blockage to the membrane pores.21,26-28 To remove reversible fouling, backflushing and air spargin are usually employed.29 However, the higher attachment of foulants caused by EOM decreases membrane filtration efficiency due to either too frequent back-flushing stages or unsustainable values of specific air demand (SAD) of the membrane.30 Moreover, irreversible fouling can only be removed by chemical cleaning, 31 which is non-desirable since excessive use of reagents deteriorates the membrane. EOM production has been extensively assessed in traditional wastewater treatment techniques. However, EOM characterisation in microalgae cultivation technology has been far less investigated, especially in the case of continuous MPBR operation.23 EOM includes polysaccharides, proteins, nucleic acids, amino acids and peptides, among others 32,33 and is usually excreted in the microalgae culture as a result of cell growth.23,13 However, the release of EOM has been reported to be boosted under stressing conditions such as unfavourable $\mathrm{pH}$, temperatures, high or low light intensities, nutrient limitation, 34,35 the presence of toxic substances36 or high biomass content.37 Biomass (BRT) and hydraulic retention time (HRT) have been also reported to affect EOM production,26,23 but to the best of our knowledge, stress factors that increase EOM production haves not been previously evaluated in mixed cultures used for wastewater treatment. From all possible factors, temperature variations can be of great interest in outdoor large-scale microalgae cultivation applications due to the variable conditions microalgae are exposed to.38,39 In addition, the activity of nitrifying bacteria in a microalgae culture has been reported to affect microalgae performance.16 Nevertheless,the influence of microalgae stress due to nitrification on EOM production has not been evaluated previously. Apart from affecting membrane filtration, EOM increases the organic matter concentration of wastewater, 40 which can hinder microalgae activity by favouring the growth of microalgae- competing organisms such as heterotrophic bacteria and grazers.41,23 Bacteria can also produce compounds harmful to microalgae such as toxins,32 while grazers devour the microalgae cells, 42 meaning that EOM production can affect the robustness of the microalgae culture. EOM also increases the aggregation capacity of microalgae to the PBR surface, reducing the light available to the culture 26,12 and can complicate microalgae nutrient uptake.43 Since EOM can deteriorate both the microalgae culture and the filtration process, it is important to determine the specific conditions and factors which affect EOM production in order to improve outdoor membrane photobioreactor (MPBR) performance. The aim of this study was adding some useful information related to the factors that influence the production (and release) of excessive amounts of EOM, as well as the possible effects of this EOM on microalgae cultivation and membrane filtration, which still remains unclear in the case of large-scale membrane-based microalgae cultivation systems for wastewater treatment. To achieve this goal, lab-scale experiments were first carried out to analyse the isolated effect of temperature, nutrient limitation and nitrification from other possible stressing factors that could also affect the Chlorella-dominated culture. Later, continuous operation of an outdoor flat-panel MPBR plant that treated effluent from an AnMBR was carried out in order to evaluate the behaviour of the microalgae culture, which was affected by several stressing factors simultaneously.

\section{Material and methods}

\subsection{Microalgae and substrate}

The microalgae substrate, the characteristics of which are shown in Table A.1, was obtained from an AnMBR pilot plant in the Carraixet WWTP. ${ }^{3}$ The AnMBR effluent was aerated prior o being fed to the PBRs in order to oxidise the sulphide to sulphate, due to its toxic nature to microalgae. 44 The organic matter loading was mainly inert (Table A.1), thus boosting photoautotrophic metabolism typical of microalgae. 45 However, the presence of EOM in the microalgae culture made the soluble COD concentration to be $144 \pm 69 \mathrm{mg} \mathrm{COD} \cdot \mathrm{L}^{-1}{ }^{11}$ This organic matter favoured the activity of heterotrophic bacteria, 46 which should have degraded some of the EOM produced by microalgae. Microalgae inoculum was obtained from the walls of the secondary clarifier of the Carraixet WWTP. It consisted of a complex ecosystem which contained green 
microalgae, cyanobacteria, heterotrophic and autotrophic bacteria amongst others. The inoculum was previously adapted to the substrate as described in González-Camejo et al. ${ }^{47}$ Later, microalgae were seeded in an outdoor membrane photobioreactor (MPBR) plant (described in section 2.2.2) in which microalgae evolved to be dominated by green microalgae Chlorella, although heterotrophic and autotrophic bacteria were still present in low concentrations. ${ }^{11}$

\subsection{Experimental design}

Two sets of experiments were conducted using a Chlorella-dominated culture obtained from the MPBR plant described in section 2.2.2: i) the first group of experiments was set under lab conditions to isolate the effect of temperature variations, nutrient limitation and nitrification from other possible stressing factors that could affect microalgae under more complex outdoor conditions; ii) the second experiment was up-scaled to a continuously operated outdoor flat-panel MPBR plant that treated effluent from an AnMBR (section 2.1). In this case, the Chlorelladominated culture was affectedby several stressing factors simultaneously.

\subsection{Lab experiments}

The experimental lab-scale design was based on three stress factors: temperature, nutrient limitation and microalgae-bacteria competition. A total of 5 Experiments were carried out to evaluate the evolution of EOM production: Experiments 1, 2 and 3 focused on analysing the effect of different temperatures $\left(25,30\right.$ and $\left.35^{\circ} \mathrm{C}\right)$; Experiment 4 evaluated the effect of nutrient limitation at 25 and $30^{\circ} \mathrm{C}$; while Experiment 5 analysed the effect of microalgae- nitrifying bacteria competition. Each experiment lasted 5 days and was conducted in two 2-L Pyrex flasks: R-A and R-B. In both flasks, the culture was mixed and aerated with $0.2 \mu \mathrm{m}$ pre-filtered air using a membrane air-pump to assure homogenisation and prevent cell sedimentation and biofilm forming on the walls. The airstream was bubbled into the reactors at a flow rate of $0.5-0.6 \mathrm{vvm}$ through fine bubble diffusers placed crosswise on the bottom. Pure $\mathrm{CO}_{2}(99.9 \%)$ was injected into the air flow from a cylinder pressurised at 1.5-2 bar to provide both inorganic carbon and maintain $\mathrm{pH}$ at $7.5 \pm 0.1$ in the cultures. Four white LED lamps (18 W, 6000-6500 K) were placed vertically 20 $\mathrm{cm}$ away from the flasks to supply a light intensity of $125 \mu \mathrm{mol} \cdot \mathrm{m}^{-2} \cdot \mathrm{s}^{-1}$ on the PBR surface in 12:12 light:dark cycles. Both reactors were seeded by $1.5 \mathrm{~L}$ of microalgae substrate (section 2.1) and $0.5 \mathrm{~L}$ of microalgae culture from the outdoor MPBR plant described in section 2.2.2. As lab experiments were carried out in different time periods, each experiment started-up using microalgae cultures with different nutrient and biomass concentrations (Table A.2). However, R-A and R-B were identical in each experiment. For this reason, R-A was used as reactor control and maintained at $25^{\circ} \mathrm{C}$ to compare it with $\mathrm{R}-\mathrm{B}$, which was operated at different conditions than R-A (temperature or nitrifying bacteria competition) as explained in Table 147 A.3.

Experiment 4 was operated in batch conditions in order to reach nutrient-limited conditions during the experiment. On the other hand, the rest of experiments were fed in semi-continuous mode maintaining an HRT of $3 \mathrm{~d}$. It should be specified that in Experiments 1 and 2, temperatures were maintained constant during all the experiment. On the other hand, in R-B of Experiment 3, temperature was set at $25^{\circ} \mathrm{C}$ except for 4 hours a day in which it was risen to $35^{\circ} \mathrm{C}$ to simulate the behaviour of temperature under outdoor conditions. ${ }^{39}$ In these experiments, $5 \mathrm{mg} \cdot \mathrm{L}^{-1}$ of allylthiourea (ATU) were added to the inoculum to inhibit nitrification, 39,48 in both reactors in similar way. In Experiment $5,10 \mathrm{mg} \cdot \mathrm{L}^{-1}$ of ATU were added in R-A to assure complete nitrification inhibition, while R-B was kept without any ATU to allow nitrification to occur (Table A.3). The effect of temperatures lower than $25^{\circ} \mathrm{C}$ on EOM evolution was not evaluated as previous study 39 showed no significant differences in microalgae performance when the culture was under temperatures in the range $15-25^{\circ} \mathrm{C}$. In addition, $35^{\circ} \mathrm{C}$ was selected as a representative value of temperature stress according to previous results. ${ }^{39}$ Hence, it was not considered necessary to test higher temperatures to evaluate EOM production under microalgae stress.

\subsubsection{Pilot plant experiments}

The MPBR plant was installed in the Carraixet WWTP and consisted of two flat-plate PBRs connected to a membrane tank (MT). Each PBR had a working volume of $230 \mathrm{~L}$ and was continuously stirred by $\mathrm{CO}_{2}$-enriched air to maintain $\mathrm{pH}$ values at $7.5 \pm 0.3$ and provide carbon-replete conditions. Aeration also prevented wall fouling and ensured culture 
homogenisation. The 14-L MT contained one hollow-fibre ultrafiltration membrane bundle extracted from an industrial-scale membrane unit (PURON®) Koch Membrane Systems (PURPSH31), $0.03 \mu \mathrm{m}$ pores) with a filtration area of $3.4 \mathrm{~m}^{2}$. Further details of the MPBR plant can be found in González-Caamejo et al. ${ }^{11}$.

The operation was preceded by a start-up phase ${ }^{10}$ (data not shown) and lasted 16 days (Period A), after which culture deterioration occurred. Consequently, another start-up phase was carried out (data not shown) and the operation continued for another 18 days (Period B) to compare MPBR behaviour during both periods. This start-up phase also included a chemical cleaning of the PBRs and membranes following the steps described in González-Camejo et al. 10 . BRT and HRT were maintained at 2 and $1.25 \mathrm{~d}$, respectively.

The membrane was operated continuously at gross $20^{\circ} \mathrm{C}$-standardised transmembrane flux (J20) of around 15-18 LMH and average specific air demand (SADP) of around $16-20 \mathrm{Nm}^{3} \cdot \mathrm{m}^{-}$ 3

permeate (0.3-0.4 $\left.\mathrm{Nm}^{3} \cdot \mathrm{m}^{-2} \cdot \mathrm{h}^{-1}\right)$.

Only the amount of permeate needed to maintain hydraulic 
retention time (HRT) of 1.25 days was taken out of the plant, while the rest was recirculated to the PBRs in order to analyse the filtration process. In addition, the corresponding amount of microalgae culture was purged every day to maintain a biomass retention time (BRT) of 2 days. The membrane followed a sequence of filtration-relaxation $(F-R)$ cycles (i.e. 250 s filtration and $50 \mathrm{~s}$ relaxation). Moreover, $40 \mathrm{~s}$ of back-flush every $10 \mathrm{~F}-\mathrm{R}$ cycles, $60 \mathrm{~s}$ of ventilation every $20 \mathrm{~F}-\mathrm{R}$ cycles and $60 \mathrm{~s}$ of degasification every $50 \mathrm{~F}-\mathrm{R}$ cycles were carried out. ${ }^{10} \mathrm{In}$ order to evaluate the daily evolution of EOM concentration during the continuous operation of the MPBR plant, grab samples were collected in duplicate at 09:00 (A), 13:00 190 on days $9,10,12,16,24,25,27,31$ and 32 .

\subsection{Analytical methods}

A total of 162 samples were analysed from both the lab scale and the outdoor MPBR plant. All the samples were first filtered through a $0.45 \mu \mathrm{m}$ pore-size glass fibre filters (Millipore) to measure EOM content and nutrient concentrations ( $\mathrm{NH}_{4}-\mathrm{N}, \mathrm{NO}_{3}-\mathrm{N}, \mathrm{NO}_{2}-\mathrm{N}$ and $\left.\mathrm{PO}_{4}-\mathrm{P}\right)$. Totalsuspended solids (TSS) were measured as a proxy of biomass. ${ }^{49}$ All the measurements were determined from duplicate samples.

\subsubsection{EOM polysaccharide (EOM-POL)}

The polysaccharide content was measured by the phenol/sulfuric acid method ${ }^{50}$ with glucose (Panreac) as the standard for the calibration curves to determine polysaccharide concentration. two $\mathrm{mL}$ of filtered sample were pipetted into a colorimetric tube, and $0.05 \mathrm{~mL}$ of $80 \%$ phenol added. Then, $5 \mathrm{~mL}$ of concentrated sulfuric acid was injected onto the sample surface. The tubes were allowed to stand $10 \mathrm{~min}$ before readings were taken. The absorbance of the characteristic yellow-orange sample (Fig. A.1c) was measured at $490 \mathrm{~nm}$ for hexoses in a Perkin Elmer Lambda 35 spectrophotometer by comparing to the standard to convert to polysaccharide concentration. It was found that if nitrite concentration of the culture reached values over $2 \mathrm{mg}$ $\mathrm{N} \cdot \mathrm{L}^{-1}$, the sample got dark (Fig. A.1b). The measurement of the absorbance was thus modified. For this reason, if samples had significant nitrite concentrations, they were diluted with distilled water prior to apply the phenol/sulphuric acid method.

\subsubsection{EOM protein (EOM-P)}

The Lowry method as modified by Peterson ${ }^{51}$ was used to measure the protein content of EOM. This method consists of two chemical reactions. The first one is the biuret reaction, in which the alkaline cupric tartrate reagent complexes with the peptide bonds of the protein. And the second one is the reduction of the Folin \& Ciocalteu's phenol reagent, which yields a purple color. 1 $\mathrm{mL}$ of the filtered sample was placed in a tube with $1 \mathrm{~mL}$ of Lowry reagent. The tube was vortexed and $0.5 \mathrm{~mL}$ of Folin reagent was added after $20 \mathrm{~min}$ at room temperature. After 30 in in darkness at room temperature (to prevent Folin reagent degradation), the absorbance of the sample was measured at a wavelength of $750 \mathrm{~nm}$ in a Perkin Elmer Lambda 35 spectrophotometer. Bovine serum albumin (BSA) was used as the protein standard for the spectrophotometry calibration curves. The absorbance value was converted to protein concentration using the calibration curve. ${ }^{52}$ In this case, if allylthiourea $\left(\mathrm{C}_{4} \mathrm{H}_{8} \mathrm{~N}_{2} \mathrm{~S}\right)$ is used to inhibit $A O B$ growth in the microalgae culture $^{48}$ in concentrations higher than $5 \mathrm{mg} \cdot \mathrm{L}^{-1}$, the sample gets darker (Fig. A.2). Hence, when ATU was present in the microalgae culture in significant concentrations (Experiment 5), the protein concentration of the culture was not measured.

\subsubsection{Other measurements}

Measurements of ammonium $\left(\mathrm{NH}_{4}-\mathrm{N}\right)$, nitrite $\left(\mathrm{NO}_{2}-\mathrm{N}\right)$, nitrate $\left(\mathrm{NO}_{3}-\mathrm{N}\right)$ and phosphate $\left(\mathrm{PO}_{4}-\mathrm{P}\right)$ were determined according to Standard Methods ${ }^{53} 4500-\mathrm{NH}_{3}-\mathrm{G}, 4500-\mathrm{NO}_{2}-\mathrm{B}, 4500-\mathrm{NO}_{3}-\mathrm{H}$ and 4500-P-F, respectively, in a Smartchem 200 automatic analyser (WestcoScientific Instruments, Westco). Chemical oxygen demand (COD) and TSS were determined from duplicate samples as described in Standard Methods. 53

\subsection{Calculations}

Biomass productivity (mg VSS $\left.\cdot \mathrm{L}^{-1} \cdot \mathrm{d}^{-1}\right)$, nitrogen recovery rate $(\mathrm{NRR})\left(\mathrm{mg} \mathrm{N} \cdot \mathrm{L}^{-1} \cdot \mathrm{d}^{-1}\right)$, 
phosphorus recovery rate $(\mathrm{PRR})\left(\mathrm{mg} \mathrm{P} \cdot \mathrm{L}^{-1} \cdot \mathrm{d}^{-1}\right)$ were calculated following the equations shown in González-Camejo et al. ${ }^{11}$. The daily average fouling rate $(\mathrm{FR})\left(\mathrm{mbar}^{\left.-\mathrm{min}^{-1}\right)}\right.$ is defined in Eq. 1: Where $\mathrm{TMPj}^{f}$ is the transmembrane pressure at the end of the filtration period $\mathrm{j}$ (mbar), $\mathrm{TMPj}^{\mathrm{i}}$ is the transmembrane pressure at the beginning of the filtration period $\mathrm{j}$ (mbar), $/ \mathrm{Jt}$ is the time interval of each filtration stage (250s) and $z$ is the number of filtration stages in one day. 243

\subsection{Statistical analysis}

The differences among the experiments were analysed by one-way ANOVA via SPSS software (version 14.0). $\mathrm{p}$-value $<0.05$ was considered for statistical significance.

\section{Results}

It should be noted that the EOM concentration was measured considering only polysaccharide (EOM-POL) and protein (EOM-P) concentrations, since they are the major constituents of the algae EOM. $26,54,13$ It should be also considered that microalgae performance was not compared between different experiments since each experiment started with inoculums and substrate with different characteristics (Table A.2) and were thus expected to influence microalgae performance. In addition, it should be bear in mind that the EOM concentrations measured are actually the result of the EOM released by microalgae (EOM released by bacteria is negligible) minus the EOM degraded by heterotrophic bacteria. However, the effect of EOM degradation by heterotrophic bacteria was not considered to significantly alter the results as it should similarly affect all cases in a manner as all inoculums had negligible bacteria concentration.

\subsection{Effect of temperature on EOM content}

In Experiment 1, similar trend of normalised EOM (i.e. EOM concentration divided by microalgae biomass) was observed in both R-A (25ㄷ, Fig. 1a) and R-B ( $30^{\circ} \mathrm{C}$, Fig. 1b). In fact, there were no statistically significant differences between the two temperatures for both normalised EOM-POL and EOM-P ( $p$-value $>0.05, n=9$ ). However, both reactors presented a decrease in the normalised EOM-P, which implied that the EOMPOL/EOM-P ratio increased through time from 0.8 to 2.2. When a higher temperature range between R-A and R-B was tested; i.e. 25 and $35^{\circ} \mathrm{C}$ in Experiment 2, the behaviour was similar than Experiment 1; i.e. both normalised EOM-POL

and EOM-P patterns were similar in both reactors (Fig. 1c, 1d), showing no

statistically significant differences ( $p$-value $>0.05, n=9$ ). The normalised EOM slope values were positive for polysaccharides and negative for proteins, yielding an EOM-POL/EOM-P ratio that increased from 0.5 to 1.7 in both reactors.

Lastly, when temperature increments from 25 to $35^{\circ} \mathrm{C}$ were applied to the culture only $4 \mathrm{~h}$ a day (Experiment 3), no statistical differences ( $p$-value $>0.05, n=9$ ) were found between the two reactors for EOMPOL and EOM-P concentrations (data not shown). However, when normalised EOM-POL was analysed, the pattern was statistically significantly different ( $p$-value $<0.05, n=$ 9). At $25^{\circ} \mathrm{C}$ (Control, Fig 1e), the normalised EOM-POL increase was less than $10 \%$, while it rose significantly to $42 \%$ when temperature peak was applied (Fig. 1f). In the case of normalised EOM$P$, no significant differences ( $p$-value $>0.05, n=9$ ) between both reactors were found (Fig. 1e, 1f). Similarly, to previous experiments, the EOM- OL/EOM-P ratio increased in Experiment 3 from 1.6 to 2.6 and 3.8 for R-A and R-B, respectively.

\subsection{Effect of nutrient limitation on EOM content}

In Experiment 4, reactors were operated in batch conditions at 25 (Fig. 2a) and $30^{\circ} \mathrm{C}$ (Fig. 2b) in order to reach nutrient-limited conditions; i.e. $\mathrm{NH}_{4}-\mathrm{N}$ concentration lower than $10 \mathrm{mg} \mathrm{N} \cdot \mathrm{L}^{-} 1.55$ As can be seen in Fig. 2, both EOM-POL and EOM-P concentrations increased over time in batch conditions. At $25^{\circ} \mathrm{C}$ (Fig. 1a) the increase was 6.7-fold and 2.6-fold for EOM-POL and EOM-P, respectively, from the beginning to the end of the experiment. At $30{ }^{\circ} \mathrm{C}$ (Fig. 1b), EOM-POL and EOM-P increased by 7.0-fold and 3.1-fold, respectively, presenting no significant differences in comparison to $25^{\circ} \mathrm{C}$ ( $\mathrm{p}$-value $>0.05, \mathrm{n}=9$ ). This made both reactors reach nutrient limitation on day 4 (Fig. 2). Both experiments revealed a similar gain pattern; i.e. a gradual increase of EOM production rate during the first 4 days of the experiment $\left(0.5-0.7 \mathrm{mg} \cdot \mathrm{L}^{-1} \cdot \mathrm{d}^{-1}\right.$ for EOM-POL and 
0.3-0.4 mg. $\mathrm{L}^{-1} \cdot \mathrm{d}^{-1}$ for EOM-P) and sharp increases when cultures were nutrient-limited (2.4 $\mathrm{mg} \cdot \mathrm{L}^{-1} \cdot \mathrm{d}^{-1}$ and $0.6 \mathrm{mg} \cdot \mathrm{L}^{-1} \cdot \mathrm{d}^{-1}$ for EOM-POL and EOM-P, respectively, in R-A and $2.1 \mathrm{mg} \cdot \mathrm{L}^{-1} \cdot \mathrm{d}^{-}$ 1 and $0.5 \mathrm{mg} \cdot \mathrm{L}^{-1} \cdot \mathrm{d}^{-1}$ for EOM-POL and EOM-P, respectively, in $\left.\mathrm{R}-\mathrm{B}\right)$. Since the raise of EOM$\mathrm{POL}$ production rate was significantly higher than that of EOM-P in both R-A and R-B, the EOMPOL/EOM-P ratio rose throughout Experiment 4 from 1.2 to 2.4 .

\subsection{Effect of microalgae-AOB competition on EOM content}

The competition with $\mathrm{AOB}$ was tested at $25^{\circ} \mathrm{C}$ in both reactors. As can be seen in Fig. 3 , EOM-POL evolution throughout Experiment 5 was similar in both cultures with and without $A O B$ competition ( $p$-value $>0.05 ; n=8$ ) and finally increased in both reactors by around 302

$50 \%$. OM-P content was not measured in Experiment 5 since the ATU (added to the culture to inhibit $A O B$ activity) interfered in protein measurement (see Fig. A.2).

\subsection{Effect of outdoor conditions on the EOM content}

The daily samples taken from the MPBR plant; i.e. samples A, B and C for each day did not show any specific trend in either polysaccharides or proteins for none of the periods analysed (Fig 4). Similar behaviour was found in the normalised EOM concentrations (data not shown).

Regarding the evolution of normalised EOM concentration during the continuous operation of the MPBR plant in Period A, both normalised EOM-POL and EOM-P remained under similar values until day 12 , but significantly increased on day 16 ( $p$-value $<0.05 ; n=12$ ), as displayed in Fig. 5d. However, this EOM increase on day did not seem to be related to an increase in the transmembrane pressure, which evolution is shown in Figure 6a. It should be noted that the TMP displayed in the graph only corresponds to that measured during filtration stage. The TMP measured during other stages such as relaxation and back-flushing (see Section 2.2.2) is not displayed in Fig. 6a to ease data visualisation. As can be observed in Fig. 6a, TMP started Period A with low values around 0.05 bar at the beginning of Period $A$ and increased to values in the range of 0.10-0.18 bar on day 9 on. In fact, from day 9 until the end of Period A, the TMP trend was similar, with the exception of day 11 in which maximum value of TMP got close to 0.25 bar (Fig. 6a). On the other hand, the EOM increase on day 16 did coincide with a decrease in NRR and biomass productivity (Fig. $5 b, 5 d$ ). A start-up phase ${ }^{10}$ was then carried out after day 16 , which reduced the EOM concentration significantly on day 24 (Fig. $5 \mathrm{~d}$ ). The transmembrane pressure of the membrane also decreased to values in the range of 0-0.04 bar (Fig. 6a) due to the membrane chemical cleaning done during this start-up phase (as explained in Section 2.2.2). Once again, the normalised EOM concentrations remained at similar values for around two weeks but rose by the end of Period B (Fig. 5d). However, at this time, only EOM-POL concentration increased significantly ( $p$-value $<0.05 ; n 329=15$ ), while EOM-P concentration remained nearly stable. On the other hand, MPBR performance (in terms of nutrient recovery and biomass productivity) decreased with time in Period B, similarly to what occurred in Period A (Fig. 5b). Solar light PAR and culture temperature were monitored during the continuous operation of the MPBR plant (Fig. $5 a)$. In the first 10 days, the conditions were favourable for microalgae growth; i.e. solar light intensities of around $400 \mu \mathrm{mol} \cdot \mathrm{m}^{-2} \cdot \mathrm{s}^{-1}$ and mid-range temperatures of around $20^{\circ} \mathrm{C}$. However, after day 10, the ambient conditions changed (temperature increased round $5^{\circ} \mathrm{C}$ and solar PAR suffered a significant reduction) and probably favoured nitrifying bacteria growth. ${ }^{16}$ In addition, the culture was expected to be under ammonium-limited conditions, since $\mathrm{NH}_{4}-\mathrm{N}$ concentration was under $10 \mathrm{mg} \mathrm{N} \cdot \mathrm{L}^{-1} .55$ This situation made the nitrification rate (NOxR) (which measures the nitrate and nitrite produced through nitrification and is used as an indicator of nitrifying bacteria activity 16,56 increase during Period $A$ to a maximum of $9.3 \mathrm{mg} \mathrm{N} \cdot \mathrm{L}^{-1} \cdot \mathrm{d}^{-1}$ (Fig. 5a). In Period B, after the aforementioned start-up phase, the nitrification rate showed low values, but immediately increased again (Fig. 5a). A summary of the average results obtained during the continuous operation of the MPBR plant is displayed in Table A.4.

\section{Discussion}

It has to be considered that EOM products may be classified into different categories according to the phase in which they are released: compounds produced as a result of substrate metabolism are growth-synonymous and growth-associated, while those excreted due to environmental interaction and lysis are growth-independent. 37 Increasing growth- synonymous EOM would entail raised biomass concentrations. Hence, variations of normalised EOM will not 
consider the evolution of growth-synonymous EOM. ${ }^{11}$ On the other hand, growth-independent EOM will not be directly related to microalgae biomass but to microalgae stress. Normalised EOM can thus be used as an indicator of microalgae stress. ${ }^{11}$

4.1 Effect of temperature on the EOM content

According to Experiments 1 and 2, the Chlorella-dominated culture did not significantly vary heir normalised EOM-POL and EOM-P when the temperature was maintained constant at $25,30^{\circ} \mathrm{C}$ or $-35^{\circ} \mathrm{C}$. These results disagrees with those found by other authors who concluded that the EOM content is affected by temperature. ${ }^{37}$ It is possible that the microalgae had adapted to the temperatures evaluated in these experiments and were thus not significantly stressed at constant temperatures of 25,30 and $35^{\circ} \mathrm{C}$. On the other hand, statistically significant differences ( $p$-value $<0.05, n=9$ ) were found in the culture subjected to a sharp temperature increase from 25 to $35^{\circ} \mathrm{C}$ for $4 \mathrm{~h}$ a day (R-B in Experiment 3 ). This changes in temperature greatly boosted the release of normalised EOM- POL over that of the reactor control (R-A), which suggested that the culture should have suffered stress due to those temperature variations. This stress factor must be thus considered when operating large-scale microalgae cultivation systems since temperature variations over $10^{\circ} \mathrm{C}$ are easily reached outdoors. ${ }^{39}$

\subsection{Effect of nutrient concentrations on EOM content}

Since nutrient levels have been reported to play a significant role on EOM production and composition. 32,57 batch cultures (Experiment 4) made it possible to analyse the behaviour of EOM production under nutrient-replete and nutrient-deplete conditions. In nutrient-replete conditions (days 1-4), EOM increased as a consequence of the biomass accumulating in the system and hence must have been growth-synonymous. 37,11 However, when the microalgae reached nutrient-deplete conditions at $\mathrm{NH}_{4}-\mathrm{N}<10 \mathrm{mg} \mathrm{N} \cdot \mathrm{L}^{-1}, 55$ by the end of the experiments, there was a sudden increase in EOM-POL production in both reactors (Fig. 2), which suggests that under nutrient-deplete conditions EOM-POL production was not only due to microalgae growth (growth-synonymous), but also that nutrient depletion was likely to have stressed the culture. As some authors have pointed out, the lack of nutrients (especially nitrogen) may redirect the carbon metabolism towards incorporation into polymers, increasing the sugar accumulated in the cells ${ }^{32}$ and consequently, higher amounts of EOM-POL were likely to be released in the medium. This statement is also interesting regarding the up-scaling of microalgae cultivation. It suggests that if EOM concentration wants to be maintained low in order to avoid culture deterioration, nutrient-deplete conditions should be avoided. Although some studies found EOM-P to be more important than EOM-POL in both wastewater aerobic or anaerobic sludge 58,28 and microalgae cultivation experiments, ${ }^{13}$ in the present study with microalgae fed with AnMBR effluent, EOM-POL production was higher than that of EOM-P. In fact, the EOM-POL/EOM-P ratio increased in all the lab experiments by as much as 3-fold. It therefore seems that products of a polysaccharide nature are preferentially released into the medium over proteins. Similar results were obtained by Felipe Novoa et al. 26 , who reported EOM-POL/EOM-P values in the range of 1.9-4.9.

\subsection{Effect of nitrifying bacteria-microalgae competition on EOM content}

Bacteria have been suggested to have a significant effect on the EOM secretion process. ${ }^{35}$ The interspecies competition between microalgae and nitrifying bacteria for nutrients may thus affect both the uptake and the release of EOM. For this reason, the other stress factor tested under lab conditions was the microalgae-AOB competition at the optimal temperature in nutrient-replete conditions since this competition can play a significant role when treating effluents from anaerobic digestion. $39,16,59$

No significant differences were observed in EOM production in the lab-scale experiments. These results could be explained by two possible hypotheses: i) either the microalgae-AOB competition did not significantly stress the microalgae; or ii) the operating conditions of this labscale experiment (experimental time, HRT, etc.) did not produce significant changes in the culture with respect to microalgae-nitrifying bacteria competition. 


\subsubsection{Daily evolution of EOM concentration}

Since EOM production has been reported as a light-dependent process. ${ }^{32}$ the daily trend of EOM concentration was expected to be similar to that of the solar PAR measurements; i.e. lower values in the morning (Sample A) and evening (Sample C) and the highest value at midday (Sample B). However, neither the EOM-POL nor EOM-P concentrations followed the same pattern as light intensity in the continuous operation. Moreover, EOM-POL concentration as variable (Fig. 4a), while EOM-P remained fairly constant (Fig. 4b). In this respect, Period A started with an EOM-POL/EOM-P ratio of 1.2 and finished it with 1.7, while Period $B$ started presenting an EOM-POL/EOM-P ratio of 0.7 but it rose to 1.7 at the end. Hence, EOM-POL was likely to be more affected by stressing factors. Similar behaviour was observed in the lab experiments (Sections 3.1, 3.2).

These results suggest that EOM production in the outdoor MPBR plant is not directly proportional to microalgae activity (i.e. growth-synonymous and growth-associated $\mathrm{EOM}^{37}$ ) and that increasing EOM production could have been related to stress factors, such as higher temperature, light limitations, ammonium depletion or competition with nitrifying bacteria.

\subsubsection{Continuous operation of microalgae cultivation}

EOM concentration raised for both polysaccharides and proteins during Period A (Fig. 5d), probably because several stress factors affected microalgae at the end of this Period (day 16): i) the average culture temperature increased by around $5^{\circ} \mathrm{C}$ at the end of Period A (Fig. 5a), reaching maximum values over $30^{\circ} \mathrm{C}$. Previous study with similar substrate and culture showed microalgae performance to decrease at temperatures over $30^{\circ} \mathrm{C} ;{ }^{39}$ ii) ammoniumdeplete conditions were reached, obtaining $\mathrm{NH}_{4}-\mathrm{N}$ values lower than $10 \mathrm{mg} \mathrm{N} \cdot \mathrm{L}^{-1}$ at the end of Period A (Fig. 5c); iii) solar PAR reduced significantly to values under $200 \mu \mathrm{mol} \cdot \mathrm{m}^{-2} \cdot \mathrm{s}^{-1}$ on days 14-15 (Fig. 5a); iv) nitrifying bacteria activity (measured by NOxR) increased during Period $A$ reaching a maximum value of $9.3 \mathrm{mg} \mathrm{N} \cdot \mathrm{L}^{-1} \cdot \mathrm{d}^{-1}$ on day 16 (Fig. 5a). All these factors could have induced cell deterioration and so could have led to higher EOM release to the culture, 33 obtaining significantly higher EOM-POL and EOM-P concentrations on day 16 than on days 9,10 and 12 (Fig. 5d). The trend of Period B regarding EOM production was similar than Period A as it increased at the end of the period. However, this increase only affected EOM-POL, while EOM-P remained at similar values (Fig. $5 \mathrm{~d}$ ). Unlike Period $A$, the temperature in Period $B$ only reached $17.2 \pm 1.3^{\circ} \mathrm{C}$, which was lower than Period A (Table A.4). Moreover, ammonium and phosphorus were in replete conditions from day 24 on (Fig. 5c). However, the nitrification rate increased with time (Fig. 5a). These results therefore suggest that EOM-POL production in Period B must have been highly influenced by the stress caused by the presence of nitrifying bacteria in the culture. This behaviour was the opposite of that observed in Experiment 5 under labconditions, in which no significant differences were found in EOM-POL concentrations between cultures with and without nitrification. There are several factors that could be responsible for this different behaviour: i) nitrifying bacteria activity highly depends on the nitrogen load, ${ }^{60}$ which was significantly higher in the MPBR plant $(H R T=1.25 \mathrm{~d})$ than in the lab-scale Experiment $(H R T=3 \mathrm{~d})$; ii) the MPBR plant achieved significantly higher biomass concentration than lab-scale reactors, therefore suffering more significant shadow effect. 61,62

Microalgae were thus likely to be more limited in the pilot plant than at lab-scale; iii) in the labscale experiment the culture only lasted $5 \mathrm{~d}$ while under outdoor conditions the operation was lengthened to 16-18 days. The age of the culture could have also affected the nitrifying bacteria proliferation as microalgae are usually better adapters to the microalgae substrate used in this study than nitrifying bacteria, according to previous results. ${ }^{39}$ As aforementioned, EOM-P stayed at similar values during Period B unlike Period A (Fig. 5d). It was hypothesised that EOM-P increased only at the end of Period A because there were several stress factors in this period that could have affected EOM production, while in Period B microalgae-nitrifying bacteria competition was the only noticeable stress factor (Fig. 5). This confirms that polysaccharides are used by microalgae to interact with the environment in preference to proteins, as observed in the lab-scale experiments (Sections 3.1,3.2) and the outdoor MPBR plant (Section 4.4.1), where the EOM$\mathrm{POL} / \mathrm{EOM}-\mathrm{P}$ ratio of the culture always increased at the end of the Experiment/Period. It should be noted that nutrient recovery rates and biomass productivity decreased at the end of both Periods $A$ and B (Fig. 5b) when normalised EOM were the highest (Fig. 5d). Similar behaviour has been observed by other authors. ${ }^{43,33}$ However, in this study, the reduction in nutrient recovery and 
biomass productivity could also have been due to other factors such as lower solar radiation and z higher nitrification rate (Fig. 5). In fact, light and competition with nitrifying bacteria have been reported to be key factors in microalgae cultivation systems.63,16,38,64 Hence, the higher normalised EOM in the culture might not have been the main factor in the lower microalgae cultivation performance observed by the end of both Periods $A$ and $B$. It will thus be necessary to monitor the system for longer operating periods and to relate all the possible factors which influence nutrient recovery and biomass productivity to properly assess the weight of each individual factor on MPBR performance.

\subsubsection{Continuous membrane filtration}

Fig. 6a shows the evolution of TMP along Period A and B. It should be remembered that TMP is the pressure that the system has to overcome due to the membrane resistance. ${ }^{65}$ On the other hand, FR measures the rate which this resistance increases during operation. The aim of membrane filtration operation will thus focus on decreasing the FR as it would increase operating costs. $^{3}$

At the beginning of Period A (days 1-5), TMP started at low values of around 0.05 bar (Fig 6a). It must be noted that there were oscillations in these parameters (Fig 6a) due to relaxation and backflushing stages which helped to reduce the cake layer in the membrane. ${ }^{21,22,29}$ This is a common behaviour that has been observed in previous operations of the MPBR plant. ${ }^{10,11}$ As continuous membrane operation goes on, TMP continuously is expected to rise due to the accumulation of foulants on the membrane. However, from day 5 until the end of Period A, TMP remained quite stable with the exception of day 11 in which a significant TMP rise was observed (Fig. 5a). With respect to Period B, TMP was maintained under 0.05 bar during all Period (Fig. 5a) since it was preceded by a chemical cleaning of the membranes. Due to this cleaning, the behaviour of the membrane concerning to FR was different for both Periods, showing higher fouling rate in Period $A$ (in the range of 6.5-7.5 mbar), where the membrane started at higher TMP than in Period B: 0.6$2.7 \mathrm{mbar}^{-1}$. These FR values are considerably low,

65 probably due to limited transmembrane flux that was operated: $15-18 \mathrm{LMH} .{ }^{11}$

It should be highlighted that for both Periods A and B, FR was significantly correlated to TSS concentration (Fig. 6b). In fact, coefficient of determination $\left(R^{2}\right)$ accounted for 0.482 and 0.772 for Period A and B, respectively. This behaviour of membrane fouling has been widely reported in previous studies, not only for MPBR systems, $26,10,57$ but also in sludge-based systems. ${ }^{28}$ On the other hand, total EOM concentration (EOM-Total; i.e. the sum of EOM-POLand EOM-P) was only correlated to FR in Period $B\left(R^{2}=0.623\right)$ but it was not in Period A (Fig. 6c). These results seem contradictory, but literature with regards to this topic is also unclear. For instance, some authors have reported the correlation between EOM concentration and membrane fouling, 27,25 but others ${ }^{23}$ did not observe a link between EOM and membrane. The different relation between EOM and $F R$ in Periods $A$ and $B$ was hypothesised to be related to the different fouling state of the membrane at the beginning of each Period. In Period A, where TMP was higher (Fig. 6a), FR was mainly dominated by the TSS concentration as there was no significant correlation between EOM-Total and FR (Fig. 6b, 6c). Maybe in this Period there was a thicker cake layer on the membrane so that the effect of EOM was negligible as much of EOM could deposit on the cake layer instead of the membrane surface itself, reducing its global impact on fouling rate. In fact, cake layer retention has been reports as the main removal mechanism of EOM in a microalgae culture. 26,66 On the other hand, in Period B both TSS and EOM were correlated, which suggested that both microalgae biomass and EOM released by microalgae had significant influence on FR, probably because the membrane started perfectly clean, which implied that EOM was more likely to block not only the membrane surface but also membrane pores. 26,67

It should also be highlighted that the correlation of EOM-Total and FR found in Period B was mainly due to polysaccharides. Indeed, EOM-POL and FR showed good correlation, i.e. $R^{2}$ of 0.593; while EOM-P showed no significant changes with FR $\left(R^{2}=0.032\right)$. Similar behavior was ound by Felipe Novoa et al. ${ }^{26}$. However, as data obtained during the continuous operation of the MPBR plant was scarce, longer operating periods should be tested to corroborate these statements.

\section{Conclusions}


The lab-scale experiments showed that sudden temperature rises from 25 to $35^{\circ} \mathrm{C}$ and nutrient limitation are stress factors and increased polysaccharide release, although protein production remained stable. On the other hand, there were no significant differences with constant temperatures in the range of $25-35^{\circ} \mathrm{C}$ and competition with nitrifying bacteria. In outdoor operation the sharp variations in the culture temperature should be thus reduced at minimum during continuous operation to avoid microalgae stress and EOM production. In addition, the competition with nitrifying bacteria seemed to produce a certain degree of stress in the microalgae culture, since nitrification rate increases were related to increasing EOM production. However, this rise was also affected by a combination of several stress factors, such as excessive temperature, reduced solar light and ammonium depletion. On the other hand, lower microalgae performance in terms of nutrient recovery and biomass productivity was observed in the MPBR plant at higher EOM concentrations, although this decay could also have been influenced by other factors. Membrane fouling was found to be related to the biomass concentration of the culture. However, fouling rate obtained under the operating conditions tested showed different behaviour concerning to EOM concentration depending on the initial transmembrane pressure (TMP). 533

\section{Acknowledgements}

This research work has been supported by the Spanish Ministry of Economy and Competitiveness (MINECO, Projects CTM2014-54980-C2-1-R and CTM2014-54980-C2-2-R) jointly with the European Regional Development Fund (ERDF), both of which are gratefully acknowledged. It was also supported by the Spanish Ministry of Education, Culture and Sport via a pre-doctoral FPU fellowship to author J. González-Camejo (FPU14/05082).

\section{References}

1. D. Puyol, D.J. Batstone, T. Hülsen, S. Astals, M. Peces and J.O. Krömer, Resource recovery from wastewater by biological technologies: opportunities, challenges, and prospects, Front Microbiol., 2017, 7, 1-23. http://dx.doi.org/10.3389/fmicb.2016.02106

2. A. Robles, M.V. Ruano, A. Charfi, G. Lesage, M. Heran, J. Harmand, A. Seco, J.P.Steyer, D.J. Batstone, J. Kim and J. Ferrer, A review on anaerobic membrane bioreactors (AnMBRs) focused on modeling and control aspects, Bioresour. Technol., 2018, 270, 612-626. 545 https://doi.org/10.1016/j.biortech.2018.09.049

3. A. Seco, S. Aparicio, J. González-Camejo, A. Jiménez-Benítez, O. Mateo, J.F. Mora, G. Noriega-Hevia, P. Sanchis-Perucho, R. Serna-García, N. Zamorano-López, J.B. Giménez, A Ruiz-Martinez, D. Aguado, R. Barat, L. Borrás, A. Bouzas, N. Martí, M. Pachés, J. Ribes. A. Robles, M.V. Ruano, J. Serralta and J. Ferrer, Resource recovery from sulphate-rich sewage through an innovative anaerobic-based water resource recovery facility (WRRF), Water Sci.

Technol. 2018, 78, 1925-1936. http://dx.doi.org/10.2166/wst.2018.492

4. P. Pretel, A. Robles, M.V. Ruano, A. Seco and J. Ferrer, Economic and environmental sustainability of submerged anaerobic MBR-based (AnMBR-based) technology as compared to aerobic-based technologies for moderate-/high-loaded urban wastewater treatment, J. Environ. Manag., 2016, 166, 45-54. https://doi.org/10.1016/j.jenvman.2015.10.004.

5. D.C. Stuckey, Recent developments in anaerobic membrane reactors, Bioresour. Technol., 2012, 122, 137-148. https://doi.org/10.1016/j.biortech.2012.05.138

6. J. Wallace, P. Champagne and G. Hall, Time series relationships between chlorophyll-a, dissolved oxygen, and $\mathrm{pH}$ in three facultative wastewater stabilization ponds, Environ. Sci.:Water Res. Technol., 2016, 2, 1032-1040. https://doi.org/10.1039/c6ew00202a

7. D. Kang, K. Kim, Y. Jang, H. Moon, D. Ju and D. Jahng, Nutrient removal and community structure of wastewater-borne algal bacterial consortia grown in raw wastewater with various wavelengths of light, Int. Biodeterior. Biodegrad., 2018 126,

10-20. 564 http://dx.doi.org/10.1016/j.ibiod.2017.09.022 
8. Y. Li, S.A. Slouka, S.M. Henkanatte-Gedera, N. Nirmalakhandan and T.J., Strathmann, Seasonal treatment and economic evaluation of an algal wastewater system for energy an nutrient recovery, Environ. Sci.: Water Res. Technol., 2019, 5 15451557. $568 \quad$ https://doi.org/10.1039/c9ew00242a

9. J.R. Price, S.K. Langroodi, Y. Lan, J.M. Becker, W.K. Shieh, G.L. Rosen and C.M. Sales, Emerging investigators series: untangling the microbial ecosystem and kinetics in a nitrogen removing photosynthetic high density bioreactor. Environ. Sci.: Water Res. Technol., 2016, 2, https://doi.org/10.1039/c6ew00078a

10. J. González-Camejo, A. Jiménez-Benítez, M.V. Ruano, A. Robles, R. Barat and J. Ferrer, Optimising an outdoor membrane photobioreactor for tertiary sewage treatment, J. Environ. Manag., 2019, 245, 76-85. https://doi.org/10.1016/j.jenvman.2019.05.010

11. J. González-Camejo, S. Aparicio, A. Jiménez-Benítez, M. Pachés, M.V. Ruano, L. Borrás, R. Barat and A. Seco, Improving membrane photobioreactor performance by reducing light path: operating conditions and key performance indicators, Water Res. 2020, 172, 115518.https://doi.org/10.1016/j.watres.2020.115518

12. A. Guldhe, S. Kumari, L. Ramanna, P. Ramsundar, P. Singh, I. Rawat and F. Bux, Prospects, recent advancements and challenges of different wastewater streams for microalgal cultivation, $J$ Environ Manage., 2017, 203, 299-315.

http://dx.doi.org/10.1016/j.jenvman.2017.08.012

13. R. Tenorio, A.C. Fedders, T.J. Strathmann and J.S. Guest, Impact of growth phases on photochemically produced reactive species in the extracellular matrix of algal cultivation systems, Environ. Sci.: Water Res. Technol., 2017, 3, 1095-1108.

https://doi.org/10.1039/c7ew00172i

14. S.C. Togarcheti, M.K. Mediboyina, V.S. Chauhan, S. Mukherji, S. Ravi, S.N. Mudliar, Life cycle assessment of microalgae based biodiesel production to evaluate the impact of biomass productivity and energy source, Resour. Conserv. Recycl., 2017, 122, 286-294. https://doi.org/10.1016/j.resconrec.2017.01.008

15. Y. Zhang, A. Kendall, J. Yuan, A comparison of on-site nutrient and energy recycling Technologies in algal oil production, Resour. Conserv. Recy., 2014, 88, 13-20. https://doi.org/10.1016/i.resconrec.2014.04.011

16. J. González-Camejo, R. Barat, D. Aguado and J. Ferrer, Continuous 3-year outdoor operation of a flat-panel membrane photobioreactor to treat effluent from an anaerobic membrane bioreactor, Water Res. 2020, 169 https://doi.org/10.1016/j.watres.2019.115238

17. S. Gupta, S.B. Pawar and R.A. Pandey, Current practices and challenges in using microalgae for treatment of nutrient rich wastewater from agro-based industries, Sci. Total Environ., 2019, 1107-1126. https://doi.org/10.1016/..scitotenv.2019.06.115

18. M.R. Bilad, A.S. Azizo, M.D.H. Wirzal, L. Jia Jia, Z.A. Putra, N.A.H.M. Nordin, M.O. 603 Mavukkandy, M.J.F. Jasni, and A.R.M. Yusoff, Tackling membrane fouling in microalgae 604 filtration using nylon 6,6 nanofiber membrane, J. Environ. Manag., 2018, 23-28.

https://doi.org/10.1016/i.jenvman.2018.06.007

19. S.A. Razzak, S.A.M. Ali, M.M. Hossain and H. deLasa, Biological $\mathrm{CO}_{2}$ fixation with production of microalgae in wastewater - A review, Renew. Sust. Energy Rev., 2017, 76, 379390. http://dx.doi.org/10.1016/j.rser.2017.02.038

20. F. Gao, W. Cui, J.P. Xu, C. Li, W.H. Jin and H.L. Yang, Lipid accumulation properties of 
Chlorella vulgaris and Scenedesmus obliquus in membrane photobioreactor (MPBR) fed with secondary effluent from municipal wastewater treatment plant, Renew. Energy, 2019, 136, . https://doi.org/10.1016/j.renene.2019.01.038

21. L. Fortunato, A.F. Lamprea and T. Leiknes, Evaluation of membrane fouling mitigation 614 strategies in an algal membrane photobioreactor (AMPBR) treating secondary wastewater $\begin{array}{llll}\text { effluent, } & \text { Sci. Total } & \text { 2019, }\end{array}$ https://doi.org/10.1016/..scitotenv.2019.134548

22. H. Gong, Z. Jin, H. Xu, Q. Yuan, J. Zuo, J. Wu and K. Wang, Enhanced membrane-based pre-concentration improves wastewater organic matter recovery: Pilot-scale performance and membrane fouling, J. Clean. Prod., 2019, 206, 307-314. https://doi.org/10.1016/j.jclepro.2018.09.209

23. Y. Luo, R.K. Henderson, P. Le-Clech, Characterisation of organic matter in membrane photobioreactors (MPBRs) and its impact on membrane performance, Algal Res., 2019, 44, 101682. https://doi.org/10.1016/j.algal.2019.101682

24. P.K. Hosseini, F.P. Shariati, H.D. Amrei and A. Heydarinasab, The influence of various orifice diameters on cake resistance and pore blocking resistance of a hybrid membrane photobioreactor (HMPBR), Sep. Purif. Technol., 2020, 235,

https://doi.org/10.1016/j.seppur.2019.116187

25. L. Wang, B. Pan, Y. Gao, C. Li, J. Ye, L. Yang, Y. Chen, Q. Hu and X. Zhang, Efficient Membrane Microalgal Harvesting: Pilot-scale Performance and Technoeconomic Analysis, J. Clean. Prod. 2019, 218, 83-95. https://doi.org/10.1016/i.jclepro.2019.01.321

26. A. Felipe Novoa, L. Fortunato, Z. Ur Rehman, T. Leiknes, T, Evaluating the effect of hydraulic retention time on fouling development and biomass characteristics in an algal membrane photobioreactor treating a secondary wastewater effluent, Bioresour. Technol., 2020, 309, https://doi.org/10.1016/j.biortech.2020.123348

27. B. Liu, F. Qu, H. Liang, Z. Gan, H. Yu, G. Li and B. Van der Bruggen, Algae-laden water treatment using ultrafiltration: Individual and combined fouling effects of cells, debris, extracellular and intracellular organic matter, J Membrane Sc., 2017, 528, 178-186.

https://doi.org/10.1016/j.memsci.2017.01.032

28. A. Robles, M.V. Ruano, J. Ribes and J. Ferrer, Performance of industrial scale hollowfibre membranes in a submerged anaerobic MBR (HF-SAnMBR) system at mesophilic and psychrophilic conditions, Sep. Purif. Technol. 2013, 104, 290-296.

http://dx.doi.org/10.1016/j.seppur.2012.12.004

29. A. Robles, M.V. Ruano, J. Ribes and J. Ferrer, Sub-critical long-term operation of industrial scale hollow-fibre membranes in a submerged anaerobic MBR (HF-SAnMBR) $\begin{array}{lllll}\text { system, Sep. } & \text { Purif. } & \text { Technol., } & \text { 2012, } & \text { 100, }\end{array}$

http://dx.doi.org/10.1016/j.seppur.2012.09.010

30. A. Robles, G. Gapson-Tojo, A. Gales, A. Viruela, B, Sialve, A. Seco, J.P. Steyer and J. 648 Ferrer, Performance of a membrane-coupled high-rate algal pond for urban wastewater treatment at demonstration scale, Bioresour. Technol., 2019, 301, 122672.

https://doi.org/10.1016/j.biortech.2019.122672

31. N. Porcelli and S. Judd, Chemical cleaning of potable water membranes: a review, Sep.

Purif. Technol. 2010, 71, 137-143. https://doi.org/10.1016/..seppur.2009.12.007

32. C. Delattre, G. Pierre, C. Laroche, and P. Michaud, Production, extraction and characterization of microalgal and cyanobacterial exopolysaccharides, Biotechnol Adv.: 2016, 34, 1159-1179. http://dx.doi.org/10.1016/j.biotechadv.2016.08.001

33. J. Sha, Z. Lu, J. Ye, G. Wang, Q. Hu, Y. Chen and X. Zhang, The inhibition effect of recycled Scenedesmus acuminatus culture media: Influence of growth phase, inhibitor identification and removal, Algal Res., 2019, 42, 101612.

https://doi.org/10.1016/j.algal.2019.101612 
34. V. Discart, M.R. Bilad, L. Marbelia and I.F.J. Vankelecom, Impact of changes in broth composition on Chlorella vulgaris cultivation in a membrane photobioreactor (MPBR) with permeate recycle, Bioresour. Technol.: 2014, 152, 321-328.

http://dx.doi.org/10.1016/j.biortech.2013.11.019

35. M. Li, W. Zhu, L. Gao and L. Lin, Changes in extracellular polysaccharide content and morphology of Microcystis aeruginosa at diffenrent specific growth rates, J. Appl. Phycol., 2013, 25, 1023-1030. https://doi.org/10.1007/s10811-012-9937-7

36. W.C. Kuo, Production of soluble microbial chelators and their impact on anaerobic treatment. PhD Thesis. lowa City: University of lowa, 1993.

37. D. J. Barker and D.C. Stuckey, A review of soluble microbial products (SMP) in wastewater treatment systems, Water Res.: 1999, 33 3063-3082. https://doi.org/10.1016/S0043$\underline{1354(99) 00022-6}$

38. A. Jebali, F.G. Acién, E. Rodriguez, E.J. Olguín, S. Sayadi and E. Molina, Pilot-scale outdoor production of Scenedesmus sp. in raceways using flue gases and centrate from 674 anaerobic digestion as the sole culture medium, Bioresour. Technol., 2018, 262, 1-8.

https://doi.org/10.1016/j.biortech.2018.04.057

39. J. González-Camejo, S. Aparicio, M.V. Ruano, L. Borrás, R. Barat and J. Ferrer, Effect of ambient temperature variations on an indigenous microalgae-nitrifying bacteria culture dominated by Chlorella. Bioresour. Technol., 2019, 290, 121788.

679 https://doi.org/10.1016/j.biortech.2019.121788

40. D. Nagarajan, D.J. Lee, C.Y. Chen and J.S. Chang, Resource recovery from wastewaters using microalgae-based approaches: A circular bioeconomy perspective. Bioresour. Technol. 682 2020, 302, 122817. https://doi.org/10.1016/i.biortech.2020.122817

41. G. Kwon, H. Kim, D. Song and D. Jahng, Co-culture of microalgae and enriched nitrifying bacteria for energy-efficient nitrification, Biochem. Eng. J. 2019, 152, 107385.

https://doi.org/10.1016/j.bej.2019.107385

42. J.G. Day, Y. Gong and Q. Hu, Microzooplanktonic grazers A potentially devastating threat to the commercial success of microalgal mass culture, Algal Res.: 2017, 27, 356-365. http://dx.doi.org/10.1016/j.algal.2017.08.024

43. N. Qureshi, B.A. Annous, T.C. Ezeji, P. Karcher and I.S. Maddox, Biofilm reactors for industrial bioconversion processes: employing potential of enhanced reaction rates, Microb. Cell Fact., 2005, 4, 24-44. https://doi.org/10.1186/1475-2859-4-24

44. J. González-Camejo, R. Serna-García, A. Viruela, M. Pachés, F. Durán, A. Robles, M.V. 693 Ruano, R. Barat and A. Seco, Short and long-term experiments on the effect of sulphide on microalgae cultivation in tertiary sewage treatment. Bioresour Technol., 2017, 244, 15-22. http://dx.doi.org/10.1016/j.biortech.2017.07.126

45. S. Rossi, F. Casagli, M. Mantovani, V. Mezzanotte and E. Ficara, Selection of photosynthesis and respiration models to assess the effect of environmental conditions on mixed microalgae consortia grown on wastewater, Bioresour. Technol. 2020, 305, 122995.

https://doi.org/10.1016/j.biortech.2020.122995

46. Y. Luo, P. Le-Clech and R.K. Henderson, Assessment of membrane photobioreactor (MPBR) performance parameters and operating conditions. Water Res., 2018, 138, 169-180. https://doi.org/10.1016/j.watres.2018.03.050

47. J. González-Camejo, R. Barat, M. Pachés, M. Murgui, J. Ferrer and A, Seco, Wastewater Nutrient Removal in a Mixed Microalgae-bacteria Culture: Effect of Light and Temperature on the Microalgae-bacteria Competition. Environ. Technol., 2018, 39, 503-515.

https://doi.org/10.1080/09593330.2017.1305001

48. I. Krustok, M. Odlare, J. Truu and E. Nehrenheim, Inhibition of nitrification in municipal wastewater-treating photobioreactors: Effect on algal growth and nutrient uptake, Bioresour. Technol., 2016, 202, 238-243. http://dx.doi.org/10.1016/j.biortech.2015.12.020 
49. Y. Ling, L.P. Sun, S.Y. Wang, C.S.K. Lin, Z. Sun and Z.G. Zhou, Cultivation of oleaginous microalga Scenedesmus obliquus coupled with wastewater treatment for enhanced biomass and lipid production, Biochem. Eng. J., 2019, 148, 162-169,

https://doi.org/10.1016/j.bej.2019.05.012

50. M. Dubois, K.A. Gilles, J.K. Hamilton, P. Rebers and F. Smith, Colorimetric method for determination of sugars and the related substances, Anal. Chem., 1956, 28, 350-356.

51. G.L. Peterson, Review of the Folin phenol protein quantitation method of Lowry, 717 Rosebrough, Farr and Randall, Anal. Biochem. 1979, 100, 201-220.

52. C.V. González, M.C. Ceron, F.G. Acien, C. Segovia, Y. Chisti and J. M. Fernández, Protein measurements of microalgal and cyanobacterial biomass, Bioresour. Technol., 2010, 101. 7587-7591. https://doi.org/10.1016/i.biortech.2010.04.077

53. APHA, Standard methods for the examination of water and wastewater, 21th. American Public Health Association, American Water Works Association, Water Environment Federation, Washington, USA, 2012.

54. G.P. Sheng, H.Q. Yu and X.Y. Li, Extracellular polymeric substances (EPS) of microbial aggregates in biological wastewater treatment systems: A review, Biotechnol. Adv., 2010, 28, 882-894. https://doi.org/10.1016/j.biotechadv.2010.08.001

55. J. González-Camejo, A. Jiménez-Benítez, M.V. Ruano, A. Robles, R. Barat and J. Ferrer, Preliminary data set to assess the performance of an outdoor membrane photobioreactor. DIB, 2019, 27, 104599. https://doi.org/10.1016/j.dib.2019.104599

56. S. Rossi, M. Bellucci, F. Marazzi, V. Mezzanotte and E. Ficara, Activity assessment of microalgal-bacterial consortia based on respirometric tests, Water Sci. Technol., 2018, 78, 207-215. https://doi.org/10.2166/wst.2018.078.

57. A.K.S. Lau, M.R. Bilad, N.B. Osman, L. Marbelia, Z.A. Putra, N.A.H.M. Nordin, M.D.H. Wirzal and A. L. Khan, Sequencing batch membrane photobioreactor for simultaneous cultivation of aquaculture feed and polishing of real secondary effluent, J. Water Process Eng. 2019, 29, 100779. https://doi.org/10.1016/j.jwpe.2019.100779

58. A. Ramesh, D.J. Lee and S.G. Hong, Soluble microbial products (SMP) and soluble 738 extracellular polymeric substances (EPS) from wastewater sludge, Appl Microbiol Biotechnol. 2006, 73, 219-225. https://doi.org/10.1007/s00253-006-0446-y

59. B. Molinuevo-Salces, M.C. García-González and C. González-Fernández, Performance comparison of two photobioreactors configurations (open and closed to the atmosphere) treating anaerobically degraded swine slurry, Bioresour. Technol. 2010, 101, 5144-5149.

https://doi.org/10.1016/i.biortech.2010.02.006

60. P. Foladori, S. Petrini and G. Andreottola, How suspended solids concentration affects nitrification rate in microalgal-bacterial photobioreactors without external aeration. Heliyon, 2020, 6, e03088. https://doi.org/10.1016/j.heliyon.2019.e03088

61. J. González-Camejo, A. Viruela, M.V. Ruano, R. Barat, A. Seco and J. Ferrer, Dataset to assess the shadow effect of an outdoor microalgae culture. DIB, 2019, 25, 104143. https://doi.org/10.1016/j.dib.2019.104143j.

62. D.L. Sutherland, J. Park, P.J. Ralph and R.J. Craggs, Improved microalgal productivity and nutrient removal through operating wastewater high rate algal ponds in series, Algal Res. 2020, 47, 101850. https://doi.org/10.1016/i.algal.2020.101850

63. A. Galès, A. Bonnafous, C. Carré, V. Jauzein, E. Lanouguère, E. Le Floc'ha, J. Pinoit, C. Poullain, C. Roques, B. Sialve, M. Simier, J.P.Steyer and E. Fouilland, Importance ecological interactions during wastewater treatment using High Rate Algal Ponds under 756 different temperate climates, Algal Res., 2019, 40, 101508.

https://doi.org/10.1016/i.algal.2019.101508 
trial integrating a sidestream microalgae process for the treatment of centrate under non optimal climate conditions, Algal Res., 2019, 39, 101430.

https://doi.org/10.1016/j.algal.2019.101430

65. A. Robles, M.V. Ruano, J. Ribes, A. Seco and J. Ferrer, Mathematical modelling of filtration in submerged anaerobic MBRs (SAnMBRs): Long-term validation. J. Membr. Sci. 2013, 446, 303-309. http://dx.doi.org/10.1016/j.memsci.2013.07.001

66. X. Zhang, M.C.E. Devanadera, F.A. Roddick, L. Fan and M.L.P. Dalida, Impact of algal organic matter released from Microcystis aeruginosa and Chlorella sp. on the fouling of a ceramic microfiltration membrane, Water Res. 2016, 103, 391-400.

http://dx.doi.org/10.1016/J.WATRES.2016.07.061

67. A. Ozkan and $\mathrm{H}$. Berberoglu, Cell to substratum and cell to cell interactions of microalgae, Colloids Surfaces B Biointerfaces., 2013, 112, 302-309.

http://dx.doi.org/10.1016/J.COLSURFB.2013.08.007

\section{Figure captions}

Figure 1: EOM-POL, EOM-P, $\mathrm{NH}_{4}-\mathrm{N}$ and $\mathrm{PO}_{4}-\mathrm{P}$ concentrations in lab-scale continuous mode. Experiment 1: a) $25^{\circ} \mathrm{C}$, b) $30^{\circ} \mathrm{C}$; Experiment 2: c) $25^{\circ} \mathrm{C}$, d) $35^{\circ} \mathrm{C}$; Experiment 3: e) $25^{\circ} \mathrm{C}$; f) 777 intervals of $10^{\circ} \mathrm{C}$ increment from 25 to $35^{\circ} \mathrm{C}$.

Figure 2: EOM-POL, EOM-P, NH4-N and $\mathrm{PO}_{4}-\mathrm{P}$ concentrations in lab-scale batch conditions (Experiment 4) at: a) $25^{\circ} \mathrm{C}$; and b) $30^{\circ} \mathrm{C}$.

Figure 3: EOM-POL, $\mathrm{NH}_{4}-\mathrm{N}$ and $\mathrm{PO}_{4}-\mathrm{P}$ in lab-scale Experiment 5: a) nitrification inhibited; and b) nitrification non-inhibited.

Figure 4. EOM concentrations and solar photosynthetically active radiation (PAR) during the continuous operation of the MPBR plant: a) EOM-POL (red); and b) EOM-P (blue).

Figure 5. Continuous operation of the MPBR plant: a) Temperature (T), solar photosynthetically active radiation (PAR) and nitrification rate $(\mathrm{NOxR})$; b) nitrogen recovery rate (NRR); phosphorus recovery rate (PRR) and biomass productivity $(\mathrm{BP}) ; \mathrm{c})$ ammonium $\left(\mathrm{NH}_{4}-\mathrm{N}\right)$ and phosphate $\left(\mathrm{PO}_{4}-\right.$ P) concentration ; d) normalised EOM-POL and EOM-P.

Figure 6. Continuous operation of the MPBR plant: a) Time evolution of transmembrane pressure (TMP); b) Fouling rate (FR) vs total suspended solids (TSS) concentrations in 790 Periods A (blue) and $\mathrm{B}$ (red); c) Fouling rate (FR) vs total EOM (EOM-Total) concentrations in 791 Periods A (blue) and $B(r e d)$. 


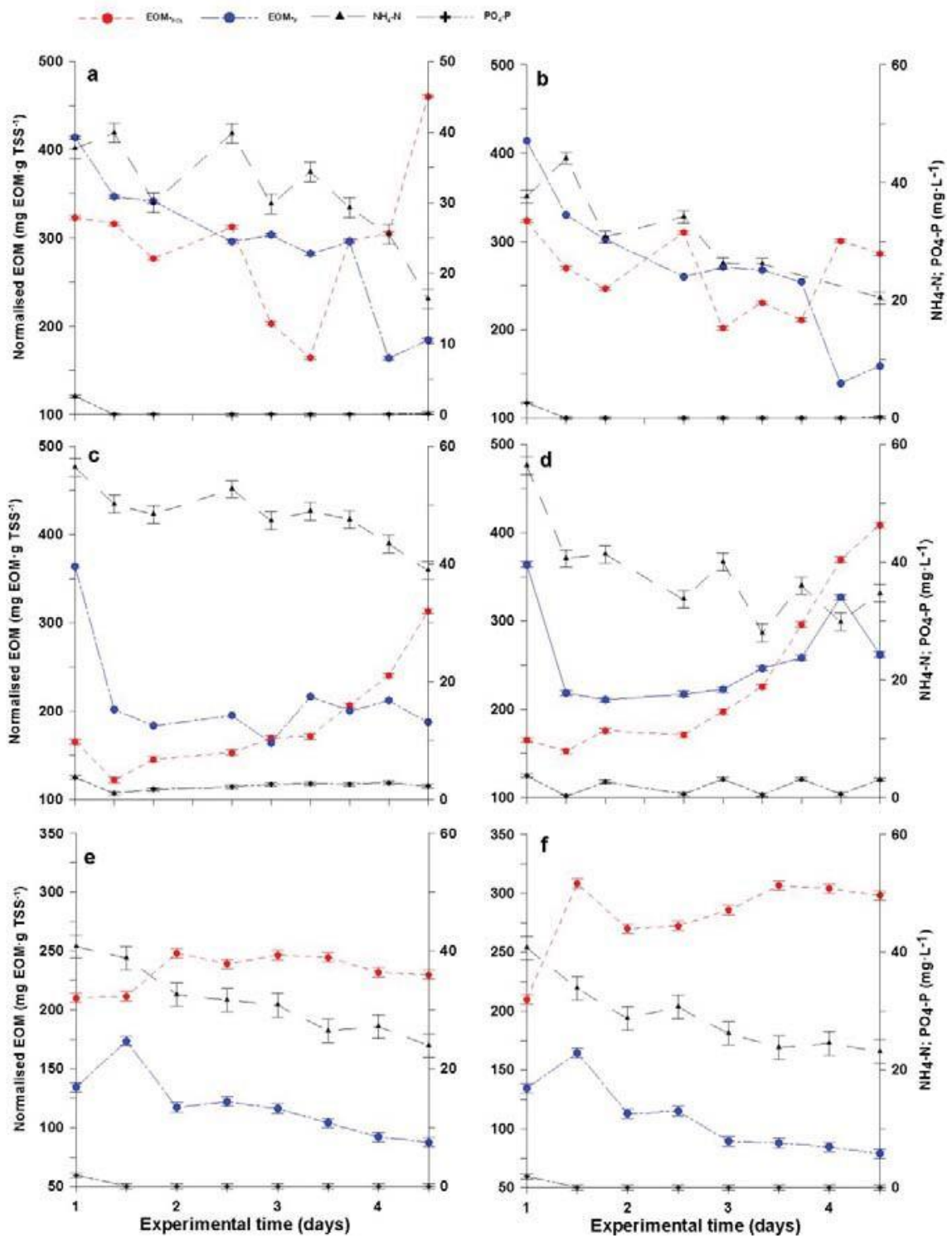

Figure 1: EOM-POL, EOM-P, NH4-N and PO4-P concentrations in lab-scale continuous mode. Experiment 1:

a) $25^{\circ} \mathrm{C}$, b) $30^{\circ} \mathrm{C}$; Experiment 2: c) $25^{\circ} \mathrm{C}$, d) $35^{\circ} \mathrm{C}$; Experiment 3: e) $25^{\circ} \mathrm{C}$; f) intervals of $10^{\circ} \mathrm{C}$ increment 


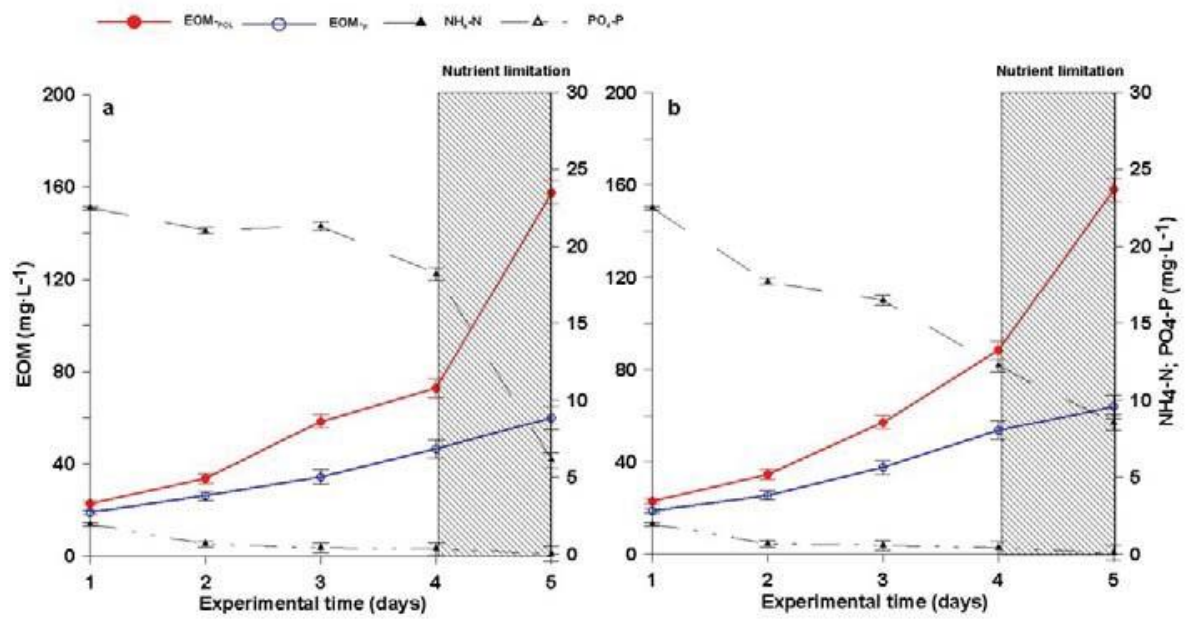

Figure 2: EOM-POL, EOM-P, NH4-N and PO4-P concentrations in lab-scale batch conditions (Experiment 4) at: a) $25^{\circ} \mathrm{C}$; and b) $30^{\circ} \mathrm{C}$. 

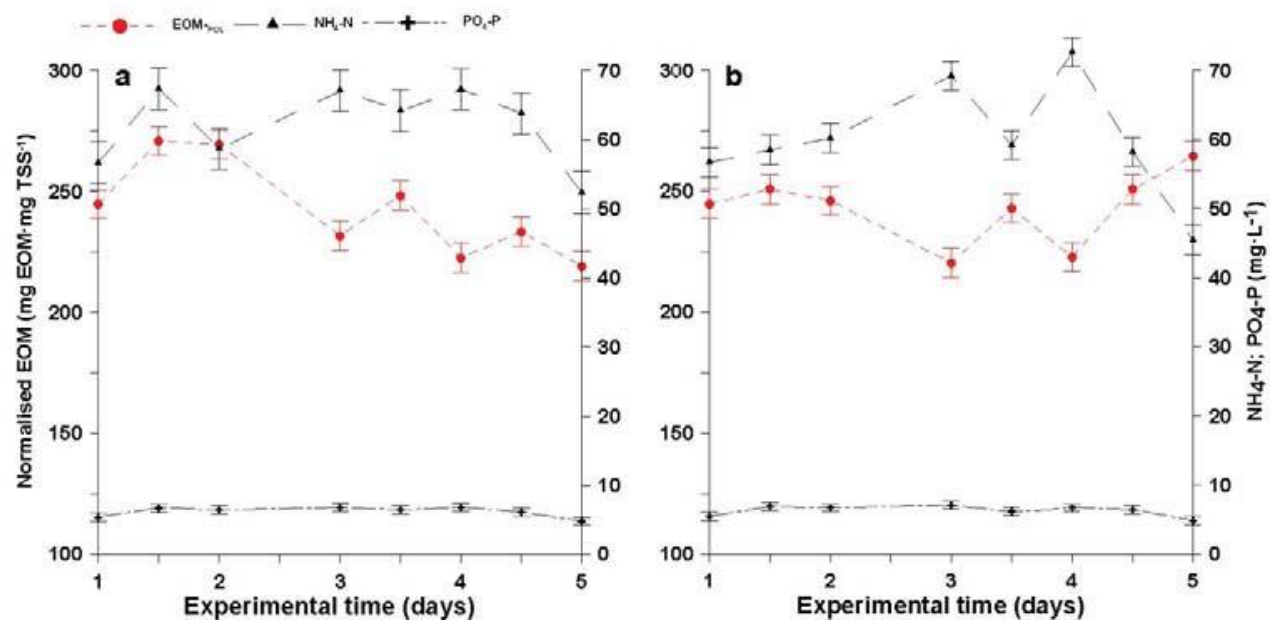

Figure 3: EOM-POL, NH4-N and PO4-P in lab-scale Experiment 5: a) nitrification inhibited; and $b$ ) nitrification non-inhibited. 


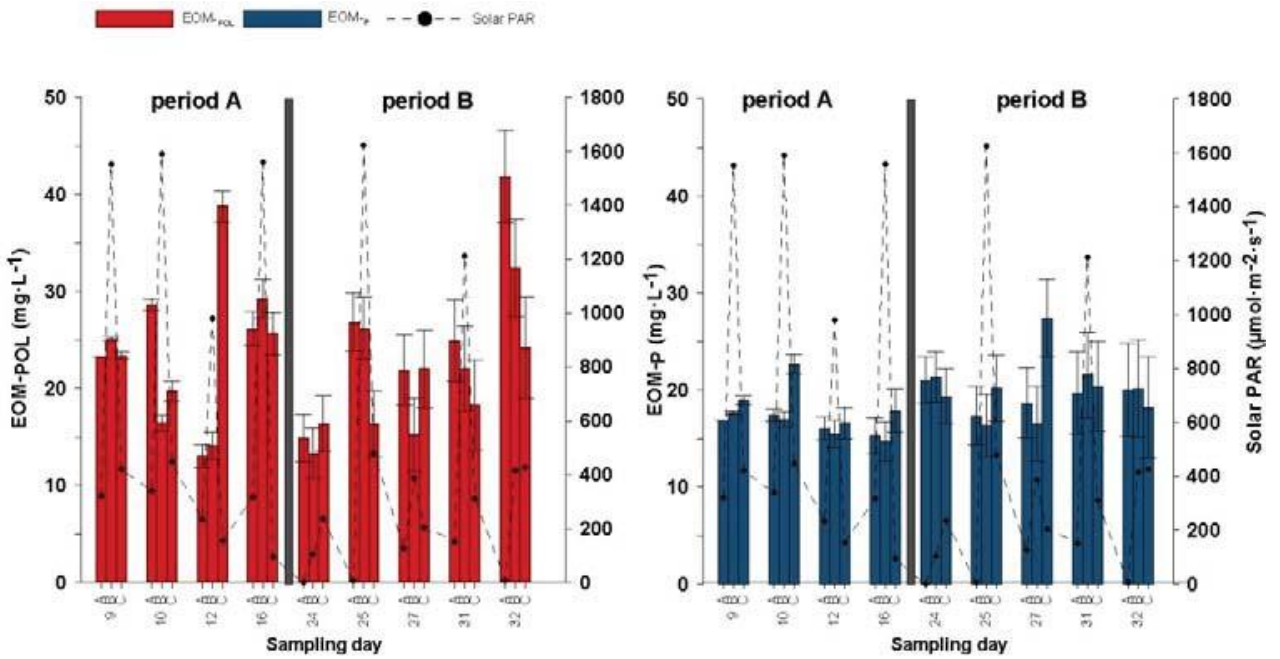

Figure 4. EOM concentrations and solar photosynthetically active radiation (PAR) during the continuous operation of the MPBR plant: a) EOM-POL (red); and b) EOM-P (blue). 

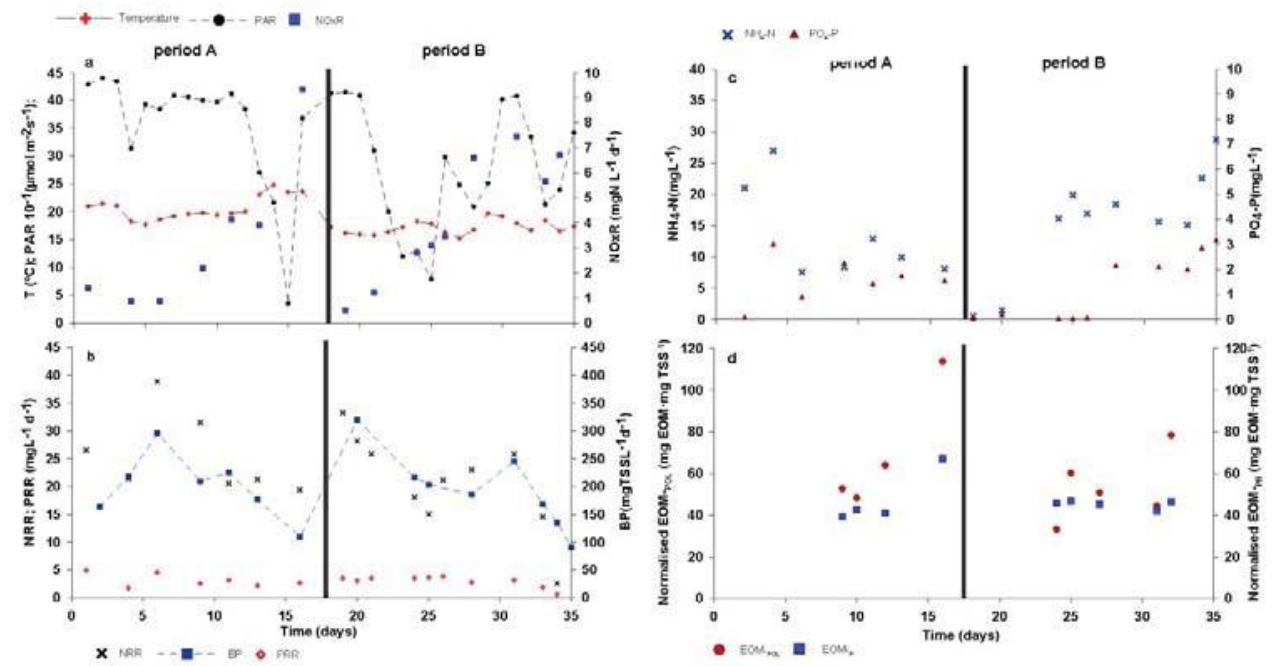

Figure 5. Continuous operation of the MPBR plant: a) Temperature (T), solar photosynthetically active radiation (PAR) and nitrification rate $(N O x R)$; b) nitrogen recovery rate (NRR); phosphorus recovery rate (PRR) and biomass productivity (BP); c) ammonium (NH4-N) and phosphate (PO4-P) concentration; d) normalised EOM-POL and EOM-P. 

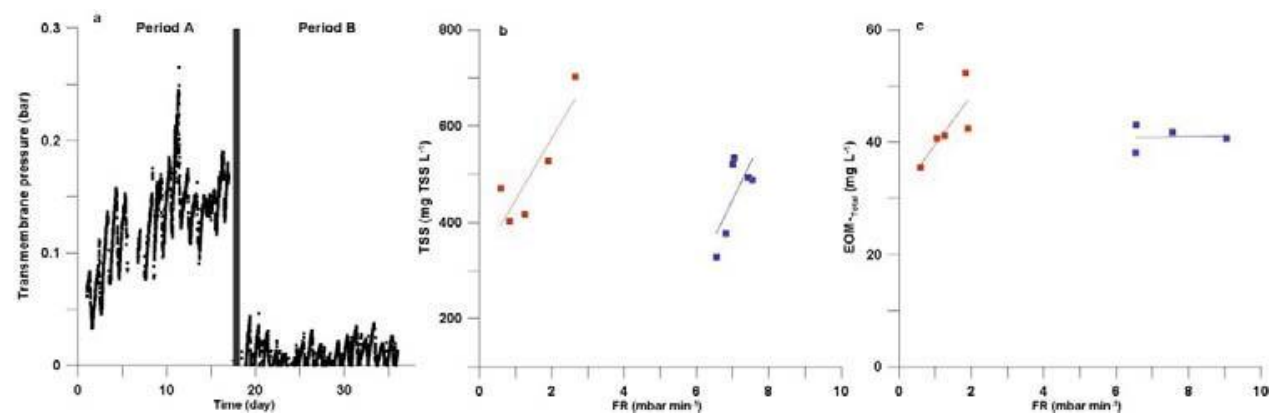

Figure 6. Continuous operation of the MPBR plant: a) Time evolution of transmembrane pressure (TMP); b) Fouling rate (FR) vs total suspended solids (TSS) concentrations in Periods $A$ (blue) and $B($ red); c) Fouling rate (FR) vs total EOM (EOM-Total) concentrations in Periods A (blue) and B (red). 